\title{
Mechanical performance of double gated injected metallic looking polypropylene parts
}

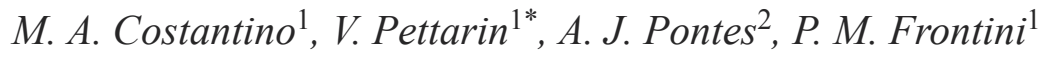 \\ ${ }^{1}$ Institute of Materials Science \& Technology (INTEMA) CONICET-University of Mar del Plata, Juan B. Justo 4302, \\ B7608FDQ Mar del Plata, Argentina \\ ${ }^{2}$ Institute for Polymers and Composites, IPC/I3N, Department of Polymer Engineering, University of Minho, Campus de \\ Azurém, 4800-058 Guimaraes, Portugal
}

Received 20 February 2015; accepted in revised form 2 July 2015

\begin{abstract}
The metallic effect obtained by incorporation of metal particles in polymers by injection molding has the advantage of eliminating post-processing techniques reducing production cost and time. Nevertheless, undesired defects in the final appearance of parts are common. In this work PP/aluminum pigments were obtained by direct injection molding and the influence of metallic particles on the aesthetic, morphological and mechanical properties of the parts was assessed. Aesthetic aspects could be improved by manipulating processing conditions: high melt temperatures diminished differential shrinkage and made weld lines less noticeable. Also at high melt temperatures Al particles increased thermal conductivity of PP generating a thicker skin, which combined with an inherent gradient temperature and typical shear stresses developed during injection molding, induced the formation of $\beta$-PP phase. Mechanical performance of parts showed to be dependent on PP morphology. Distinct deformation behaviors were seen according to the presence of PP polymorph, $\beta$-PP counteracting the detrimental effect of not bonded Al flakes, and making PP-Al moldings to have similar toughness as PP moldings with the added value of metallic looking.
\end{abstract}

Keywords: polymer composites, processing technologies, mechanical properties, fracture, morphology-performance relationship

\section{Introduction}

New materials and new technologies have been developed to eliminate the existing gaps in terms of aesthetic products. Innovation, cost and weight reduction are some factors driving for the replacement of metals by plastics. Plastics continue to offer attractive solutions for design engineers. The metallic effects of the plastics came to revolutionize the automotive industry, packaging and appliances, replacing the metal by plastic in various components. Thus, attributing the quality and prestige of the metal and adding value to products [1].

The imitation of metal by plastic has increased notably through the addition of metallic pigments in thermoplastic materials. The composite obtained has the main advantage of eliminating post-processing operations. The mixtures made of thermoplastic polymers and metal fillers represent an important group of engineering materials with a wide range of applications including electric and thermal conduction, mechanical properties and aesthetic effects. Rusu et al. [2] studied the mechanical and thermal properties of HDPE/Zinc composites. They found an increase of thermal diffusivity and thermal conductivity and a decrease of mechanical properties. Gungor [3] investigated experimentally the effect of $\mathrm{Fe}$ powder $(5,10$ and $15 \mathrm{vol} \%)$ on the physical and mechanical properties of HDPE and found that Fe

\footnotetext{
$\overline{{ }^{*} \text { Corresponding author, e-mail: pettarin@fi.mdp.edu.ar }}$

(C) BME-PT
} 
particles reduced the yield and tensile strength, percentage of elongation and Izod impact strength (notched) of HDPE. Wang et al. [4] worked with PP filled with cooper particles and reported that the presence and size of the filler influence electrical and thermal properties.

Metal particles have different sizes and shapes. Those having a plate like shape promote the increase of reflected light in a specular way, increasing the luster and metallic appearance of surfaces [5]. The appearance of flow lines and welded lines caused by the orientation of the pigment flakes perpendicularly to the surface $[6,7]$ significantly affects the appearance of the injection molded part. Adjusting the processing conditions can minimize these defects. It has been pointed out that an increase in mold and injection temperatures causes the disorientation of flakes, which in turn, attenuates weld/flow lines. The changing of size and size distribution of metal particles are alternatives to minimize these defects. Park et al. [8] carried out experimental studies of ABS plus aluminum flakes using a Jeffery model to understand the orientation kinematics of pigment flakes during the injection molding process. They found that the flake orientation has a sandwich structure due to inhomogeneous shear rate along the thickness direction, besides at the weld line zone they saw a different orientation, which is the result of fountain flow and rapid cooling near the wall. Martins et al. [9] studied the influence of the metallic particles content and type on the aesthetic properties of weld lines in PP injected molded parts and found several types of undesired effects, such as weld lines and warpage that are dependent on the type and size of particles, on the load content and also on the processing conditions used. Santos et al. [10] studied the metallic pigments influence on the aesthetic and morphological properties of the PP injected parts finding that the particles are aligned perpendicularly to the surface causing a dark line in the region of the weld line. Simultaneously they observed a change in the skin thickness especially in the case of Al pigments.

When dealing with semicrystalline polymers such as PP, morphology is an important feature since it greatly affects performance of injected parts. The morphology of melt-crystallized polymers is known to be related to the fabrication technique. In compression molding, for example, where polymers crystallize from a quiescent melt, the morphology is spherulitic. In injection molding, polymers crystallize from a melt that has been exposed to flow, shear, and temperature variations. Also, a typical structure consisting of skin, shear layer and core develops. Due to the sudden cooling of the part in the cold mold walls, the skin is characterized by very high chain orientation. The shear layer appears between the skin and the core and is characterized by having an undeveloped spherulitic structure [11]. Finally, in the core, well developed spherulitic structure is observed. In PP parts, three basic crystalline forms of $\mathrm{PP}(\alpha, \beta$, $\gamma)$ can be identified [12]. Among all crystal structures, the $\alpha$-phase obtained under ordinary industrial processing conditions is the most stable. However, $\beta$ phase is occasionally observed during crystallization from melt. It can be obtained mainly by introducing specific nucleating agents in the melt using processing equipment such as extruders [13-15] incorporating an appropriate filler in micron and nanometer scale in the melt using internal mixers and extruders [16, 17], inducing temperature gradients [18] and by shear forces in controlled flow fields [19-21]. A toughness improvement is associated to $\beta$-PP, being attributed to the development of a more perfect crystalline structure, with higher continuity of the amorphous phase and more connecting bridges between individual crystallites than a material containing solely $\alpha$-crystallites [22]; and to the occurrence of a $\beta-\alpha$ transformation during loading which is accompanied with volume contraction in respect to the related crystallographic densities [23].

Aluminum pigments have not been favored in the past for injection molded PP parts for several reasons. If they were used as powders there was always the concern that they could present a hazard. Aluminum pigments cause flow lines in injection molded parts which in most cases can not be tolerated. Even though new technologies have been developed to improve the use of metallic pigments in polymers, there is still no deep analysis of the effect of the addition of these particles in the morphological and mechanical performance of PP injected parts. Melt temperature and mold temperature affect the temperature gradient and shear rate, two variables which are inherent to the injection-molding process and which are expected to influence crystallization and polypropylene morphology [24]. Viana et al. [25] identified the significant processing variables affecting the development of the morphological parameters. They found out that the morphology 
(level of molecular orientation and degree of crystallinity) is mostly governed by the melt temperature and the degree of crystallinity of the core is essentially dominated by the mould temperature. Demiray et al. [26] studied the relationship between processing conditions and skin-core morphology of PP. They concluded that the melt temperature is the most important variable affecting the skin layer thickness and spherulite size distribution.

In this work double gated PP and PP/Al moldings were prepared varying melt and mold temperatures, as identified as the most influencing processing parameters. A complete characterization is therefore reported, which includes an aesthetical analysis, morphological evaluation and mechanical and fracture characterization. The influence of singularities induced by flow pattern such as weld lines and the injection gates on the arrangement of mechanical performance in the molding was also explored.

\section{Experimental}

\subsection{Materials and processing}

Polypropylene (PP) copolymer powder from ICORENE with specific gravity of $0.9 \mathrm{~g} / \mathrm{cm}^{3}$ and a melt flow index of $13 \mathrm{~g} / 10 \mathrm{~min}\left(190^{\circ} \mathrm{C}, 2.16 \mathrm{~kg}\right)$, was used in this study. The pigment used was Silberline 21075 aluminum flake particles of 75 microns provided by Poliversal S.A. which consists of $70 \%$ nominal weight of $\mathrm{Al}$ particles and $30 \%$ nominal weight of carrier, and is compatible with a wide range of thermoplastics. The mixture of metallic particles with $\mathrm{PP}$ was done in a rotary drum, using $2 \mathrm{wt} \%$ of metal particles; this content based on previous results [9]. Rheological performance of materials was evalu-

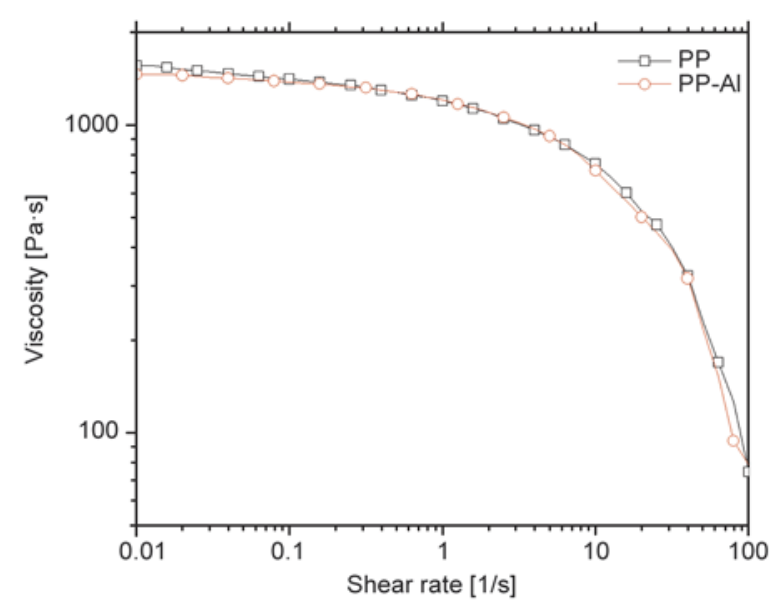

Figure 1. Rheological curves of $\mathrm{PP}$ and $\mathrm{PP}-\mathrm{Al}$ as determined in a plate-cone configuration at $220^{\circ} \mathrm{C}$
Table 1. Design of processing programme

\begin{tabular}{|c|c|c|}
\hline Condition & $\begin{array}{c}\mathbf{T}_{\text {inj }} \\
{\left[{ }^{\circ} \mathbf{C}\right]}\end{array}$ & $\begin{array}{c}\mathbf{T}_{\text {mould }} \\
{\left[{ }^{\circ} \mathbf{C}\right]}\end{array}$ \\
\hline 1 & 190 & 25 \\
\hline 2 & 190 & 40 \\
\hline 3 & 190 & 55 \\
\hline 4 & 190 & 70 \\
\hline 5 & 220 & 70 \\
\hline 6 & 220 & 55 \\
\hline 7 & 220 & 40 \\
\hline 8 & 220 & 25 \\
\hline 9 & 250 & 25 \\
\hline 10 & 250 & 40 \\
\hline 11 & 250 & 55 \\
\hline 12 & 250 & 70 \\
\hline
\end{tabular}

ated in an Anton Paar rheometer, Physica MCR301, and it was verified that PP behavior was not influenced by the presence of Al flakes (Figure 1). Two gated boxes of dimensions: $152 \mathrm{~mm}$ width, $73 \mathrm{~mm}$ length, $16 \mathrm{~mm}$ height and 1,6 $\mathrm{mm}$ thick were processed in an injection molding machine Ferromatik-Milacron K85 (injection speed $=60 \mathrm{~mm} / \mathrm{s}$; injection pressure $=45$ bar; injection time $=1 \mathrm{~s}$; packing pressure $=35$ bar; packing speed $=30 \mathrm{mms} / \mathrm{s}$; packing time $=5 \mathrm{~s}$; cooling time $=20 \mathrm{~s}$; cycle time $=$ $34 \mathrm{~s})$. To determine the influence of processing conditions on morphology and therefore in performance of moldings, injection temperature $\left(T_{\text {inj }}\right)$ and mould temperature $\left(T_{\text {mold }}\right)$ were varied following Table 1.

\subsection{Part features and defects}

The shrinkage $(S)$ of moldings was measured on a minimum of three specimens for each condition and in four different zones of the samples: three measurements in the width and one in the length. Measurements were done after 24 hours of parts processing with a digital caliper. Parts were stored in controlled temperature and humidity conditions. Shrinkage was determined using the following Equation (1):

$S_{\mathrm{L}}=\frac{l_{\mathrm{M}}-l}{l_{\mathrm{M}}}$ and $S_{\mathrm{W}}=\frac{w_{\mathrm{M}}-w}{w_{\mathrm{M}}}$

where $l$ and $w$ refers to the length and width of the part; $l_{\mathrm{M}}$ and $w_{\mathrm{M}}$ represents the mould cavity dimensions.

Also the superficial distribution of Al particles in PP moldings was observed with an optical metallographic microscope Olympus PMG3. Reflected light micrographs were analyzed with Software 'Image Pro Plus' and superficial percentage of Al particles 
was obtained from a minimum of three specimens for each condition.

\subsection{Mechanical performance}

Mechanical performance of the moldings was evaluated at different locations of the boxes to evaluate the influence of in-homogeneities. Performance was evaluated by means of the stress intensity factor $\left(K_{\text {Ic }}\right)$ plus the propagation value of the strain energy release rate $\left(G_{\mathrm{cp}}\right)$ at quasi-static conditions, and trough biaxial impact resistance $\left(I_{\mathrm{bt}}\right)$ under impact conditions. Fracture tests were carried out on mode I double edge-notched tensile specimens (DENT) cut from the moldings (nominal width, $W$, of $30 \mathrm{~mm}$, nominal crack to depth ratio, $a / W$, of 0.5 , and nominal length, $S$, of $70 \mathrm{~mm}$ ), at a crosshead speed of $2 \mathrm{~mm} / \mathrm{min}$ and room temperature in an Instron 4467 universal testing machine. Sharp notches were introduced by scalpel-sliding a razor blade having an on-edge tip radius of $13 \mu \mathrm{m}$ with a Ceast Notchvis notching machine. In order to assess influence of the weld lines in fracture, DENT samples were cut from different places of the moldings, away from weld lines, and samples including weld lines with angle between 45 and $78^{\circ}$, as depicted in Figure 2.

$K_{\text {Ic }}$ was evaluated at $5 \%$ non-linearity [27]. The load at crack initiation $F_{\mathrm{q}}$ was determined as the intercept between the load curve and the $C+5 \%$ compliance line, $C$ being the initial compliance of the
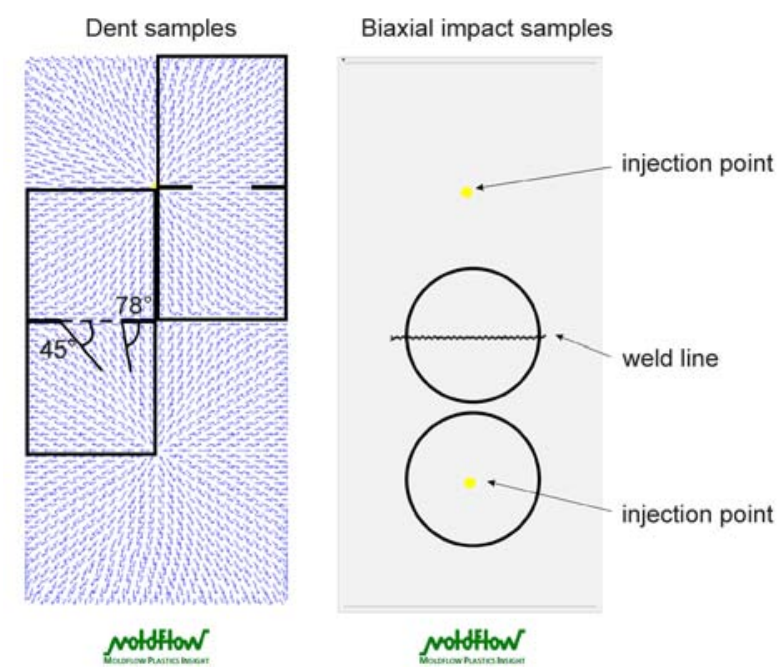

Figure 2. Location of samples cut from moldings for mechanical tests. Weld line location and flow direction in the skin were assessed using Moldflow ${ }^{\circledR}$.

load-displacement curve. The stress intensity factor at initiation, $K_{\mathrm{Iq}}$ was then determined by Equation (2):

$$
K_{\mathrm{Iq}}=\frac{F_{\mathrm{q}}}{B \sqrt{\frac{W}{2}}} f\left(\frac{a}{W}\right)
$$

where $B$ is the thickness of the sample, $W$ is the width of the sample, a is the length of the notch, and $f(a / W)$ is the function of the notch to width that for DENT samples is given by Equation (3):

$f\left(\frac{a}{W}\right)=\frac{\sqrt{\frac{\pi a}{2 W}}}{\sqrt{1-\frac{a}{W}}}\left[1.122-0.561\left(\frac{a}{W}\right)-0.205\left(\frac{a}{W}\right)^{2}+0.471\left(\frac{a}{W}\right)^{3}+0.19\left(\frac{a}{W}\right)^{4}\right]$

$G_{\text {cp }}$ was estimated from the total fracture energy, Utot, according to Equation (4) [28]:

$G_{\mathrm{cp}}=\frac{U}{B(W-a)}$

Biaxial impact performance was evaluated according to ASTM D 3763-93 procedure in two locations of the pieces (on and out of weld line) (Figure 2) using an instrumented Ceast Fractovis 6787 falling weight equipment. The specimens were clamped between two steel plates with a circular opening of $40 \mathrm{~mm}$ in diameter and tested at $3.5 \mathrm{~m} / \mathrm{s}$ and room temperature. The biaxial impact resistance, $\left(I_{\mathrm{bt}}\right)$ was calculated as the total energy to break the sample (total area over the force-displacement curve) divided thickness. Biaxial impact tests are tests on representative samples, rather than measurements of basic material properties on standard test pieces, which give a realistic view of in service impact situations being closer to real life conditions - with the additional advantage that they provide a convenient method of studying changes induced by flow in molded part performance [29, 30].

Fracture surfaces of broken samples were analyzed using a JEOL JSM-6460LV scanning electron microscope (SEM) at an accelerating voltage of $20 \mathrm{kV}$. Samples were sputter coated with a thin layer of gold before they were observed. 


\section{Results}

\subsection{Part features and defects}

Injected parts presented the typical skin-shear layercore structure of injected moldings (Figure 3). PP/Al skin thickness was larger than the one of PP moldings. This is due to the higher thermal conductivity of aluminum pigment which has been shown to increase the thermal conductivity of PP composites [31], providing a faster cooling rate and consequently an increase of the skin thickness.
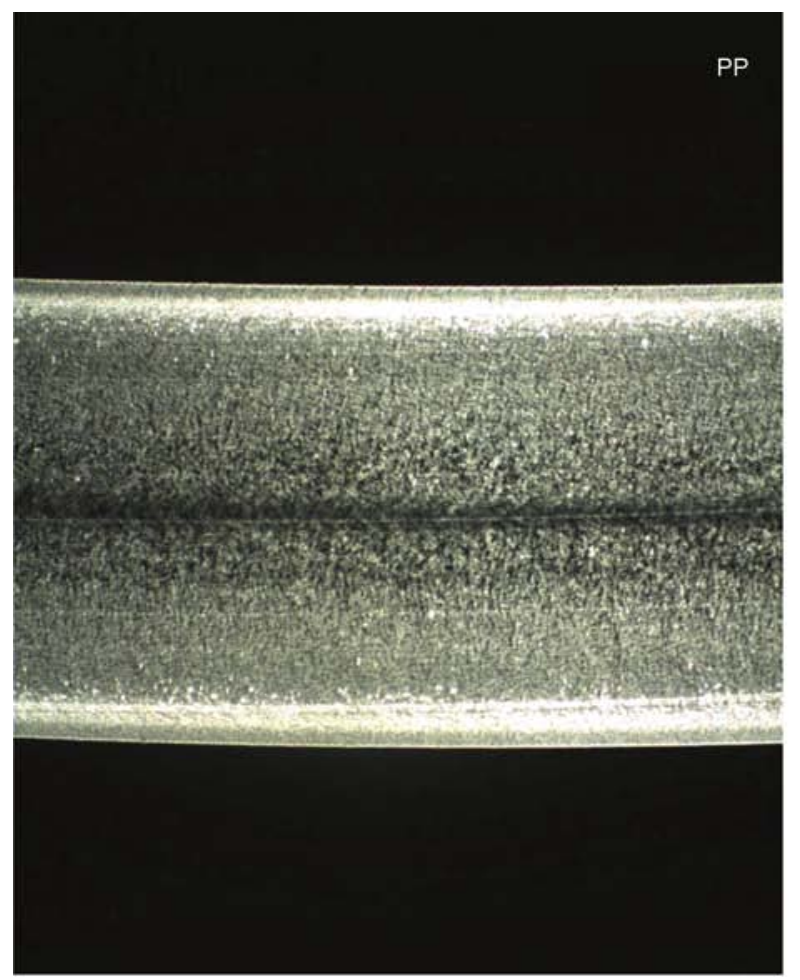

Figure 3. Trough the thickness cross-polarized optical transmission microscopies of $\mathrm{PP}$ and $\mathrm{PP} / \mathrm{Al}$
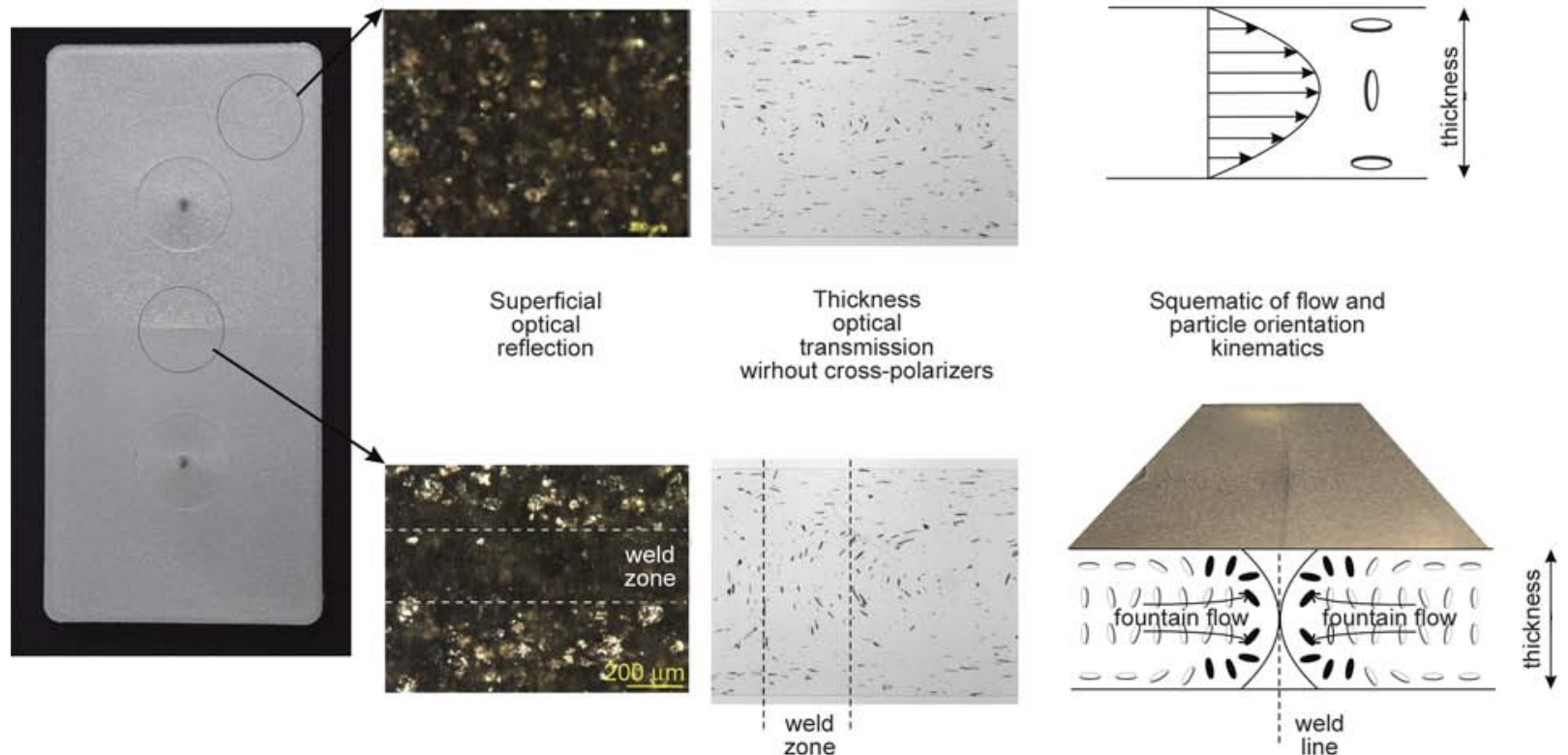

Figure 4. Optical microscopy results (reflection and transmission) with schematic of flow and particle orientation kinematics 
beneficial orientation was observed, i.e. flakes with reflecting surface parallel to part surface. All samples presented a good dispersion and orientation of pigment away from injection points and weld lines. However, at weld lines a lower amount of reflecting particles was observed in the surface (6 vs $22 \%$ away from weld line). Weld lines and flow lines became visible due to the incorporation of $\mathrm{Al}$ pigment in $\mathrm{PP}$ matrix. These observations can be explained taking into account the particles anisotropy and orientation. Particles in the core are perpendicular to the plane of the surface (Figure 4, optical transmission). In injection molding, with a symmetric velocity profile in the midplane of the thickness, the bigest shear rate occur in the skin layer (near to the mold wall) while the core is characterized by a low shear rate. Jeffery model is a model which describes the kinematics of single ellipsoidal particle suspended in a viscous liquid [32]. This model applied to a disc (where $0<L / D<<1$ ) describes that the orientation vector (normal to the disc) tends to align perpendicular to shear strain (see in Figure 4 the scheme). The melt front differs from the rest of the flow because its flow field has three-dimensional characteristics, namely the fountain-flow, which has a velocity component in the thickness direction driving the flakes at the core layer to move to the skin layer. If we have two meeting fountain flows, they result in a local region near the surface with a non parallel to the surface plane flake orientation (see scheme and micrographs in Figure 4). If the mold temperature is low and the solidification of the polymer takes place quickly, the surface orientation becomes frozen-in without any further reorientation. Thus particles remain perpendicular to the plane of the surface, and a dark line appears $[8,9]$.

Injection and mold temperatures influenced shrinkage. Shrinkage indexes of both PP and PP/Al pieces

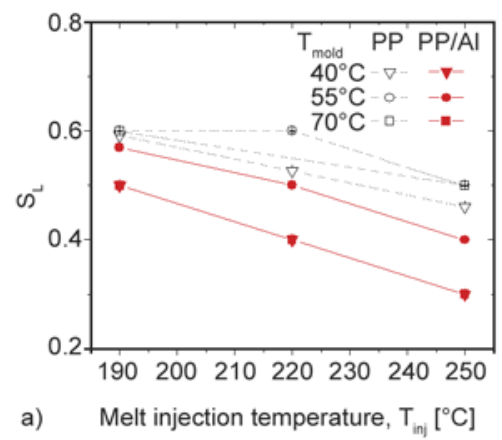

diminished with the increase of $T_{\text {inj }}$ (see Figure 5). Moreover, shrinkage indexes of $\mathrm{PP} / \mathrm{Al}$ pieces were lower than those of PP pieces, indicating higher quality of final pieces.

\subsection{Mechanical performance}

Quasi-static fracture performance of pieces depended not only on the presence or absence of Al particles, but also on the location of the samples.

At weld lines PP samples exhibited stress whitening and some plastic deformation prior to unstable failure, while PP/Al failed in a brittle manner, both following the weld line (Figure 6). In spite of differences in propagation values, i.e. GCP, fracture toughness $K_{\text {Ic }}$ of PP and PP/Al samples at the weld line were similar indicating that weld lines were predominant in fracture leading the crack growth (Table 2).

Away from weld lines, fracture behavior of PP and PP-Al were similar: a non-lineal behavior with crack stable propagation and large plastic deformation was observed for all samples (Figure 7). As in samples at weld lines, $K_{\text {Ic }}$ values were similar and differences were observed for GCP propagation values, PP pieces being a little more ductile than PP-Al moldings. Also, maximum load attained by PP-Al was

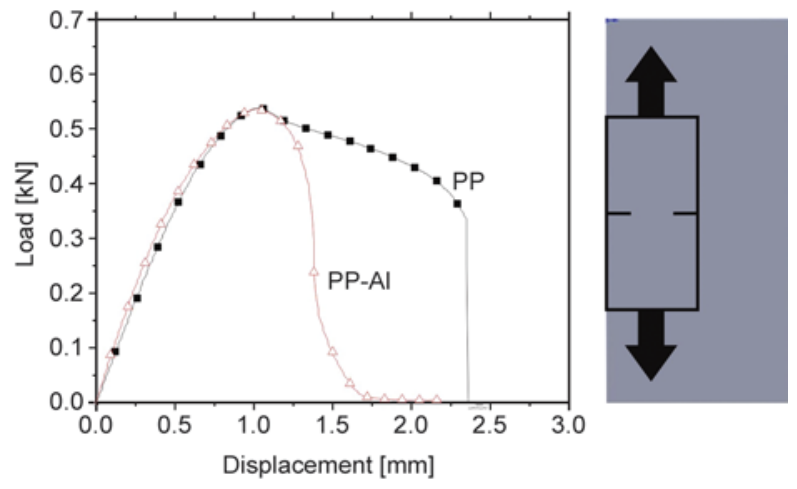

Figure 6. Typical load-displacement fracture curves at weld line for PP and PP-Al

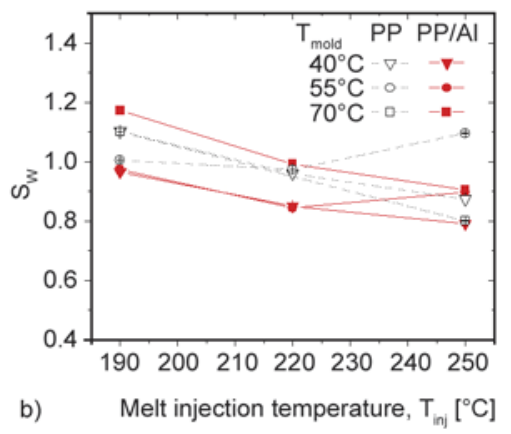

Figure 5. (a) Length and (b) width shrinkage indexes for PP and PP-Al moldings as a function of injection temperature and mold temperature 
Table 2. Mechanical and fracture parameters of boxes

\begin{tabular}{|c|l|l|r|r|}
\hline Test & \multicolumn{2}{|c|}{ Parameter } & PP & PP-AI \\
\hline \multirow{5}{*}{ Fracture } & \multirow{4}{*}{ At weld line } & $K_{\mathrm{Ic}}\left[\mathrm{MPa} \cdot \mathrm{m}^{1 / 2}\right]$ & 2.3 & 2.1 \\
\cline { 2 - 5 } & & $G_{\mathrm{cp}}\left[\mathrm{kJ} / \mathrm{m}^{2}\right]$ & 44.1 & 24.3 \\
\cline { 2 - 5 } & $\begin{array}{l}\text { Away from weld } \\
\text { Impact }\end{array}$ & $K_{\mathrm{Ic}}\left[\mathrm{MPa} \cdot \mathrm{m}^{1 / 2}\right]$ & 2.0 & 2.0 \\
\cline { 2 - 5 } & $G_{\mathrm{cp}}\left[\mathrm{kJ} / \mathrm{m}^{2}\right]$ & 87 & 75 \\
\hline \multirow{5}{*}{ line } & $U_{\text {biaxial }}[\mathrm{J} / \mathrm{mm}]$ & $\mathrm{C}-1$ & 6.7 & 2.8 \\
\cline { 2 - 5 } & Near inj point & $\mathrm{C}-2$ & 7.1 & 4.1 \\
\cline { 2 - 5 } & $\begin{array}{l}U_{\text {biaxial }}[\mathrm{J} / \mathrm{mm}] \\
\text { At weld line }\end{array}$ & $\mathrm{C}-1$ & 8.1 & 3.5 \\
\cline { 2 - 5 } & $\mathrm{C}-2$ & 3.7 \\
\hline
\end{tabular}

lower than for PP samples. An important distinct feature is the difference observed in the shape of the developed plastic zones in PP and PP-Al pieces: plastic zones of PP pieces were diamond shaped while PP-Al pieces developed elliptic plastic zones (see pictures obtained in-situ in Figure 7). Moreover, differences in propagation mode were observed in postmortem SEM of fracture surfaces. Skin and core behavior were very different, the core presenting larger plastic deformation. PP-Al injected samples presented more tearing in the core than PP mold- ings. It was also observed that $\mathrm{Al}$ particles acted as stress concentrators being not bonded to PP (Figure 8).

Due to the observed plastic behavior, fracture tests can be analyzed following the essential work of fracture (EWF) methodology, which considers the overall energy $\left(W_{\mathrm{f}}\right)$ necessary to fracture a notched specimen as made of two components: an essential one $\left(W_{\mathrm{e}}\right)$, to create new surfaces in the so-called fracture process zone, and the non-essential work $\left(W_{\mathrm{p}}\right)$ dissipated for the plastic deformation of the surrounding area, the process zone. Accordingly, the specific work, $w_{\mathrm{f}}$, can be written as the sum of two terms, as shown by Equation (5):

$w_{\mathrm{f}}=w_{\mathrm{e}}+\varphi w_{\mathrm{p}} l$

$w_{\mathrm{e}}$ and $\varphi w_{\mathrm{p}} l$ are the essential and non-essential work respectively, $\varphi$ being a shape factor and $l$ the length of the uncracked specimen width (ligament length). By performing a series of experiments on notched specimens with different ligament length $l$, an over-
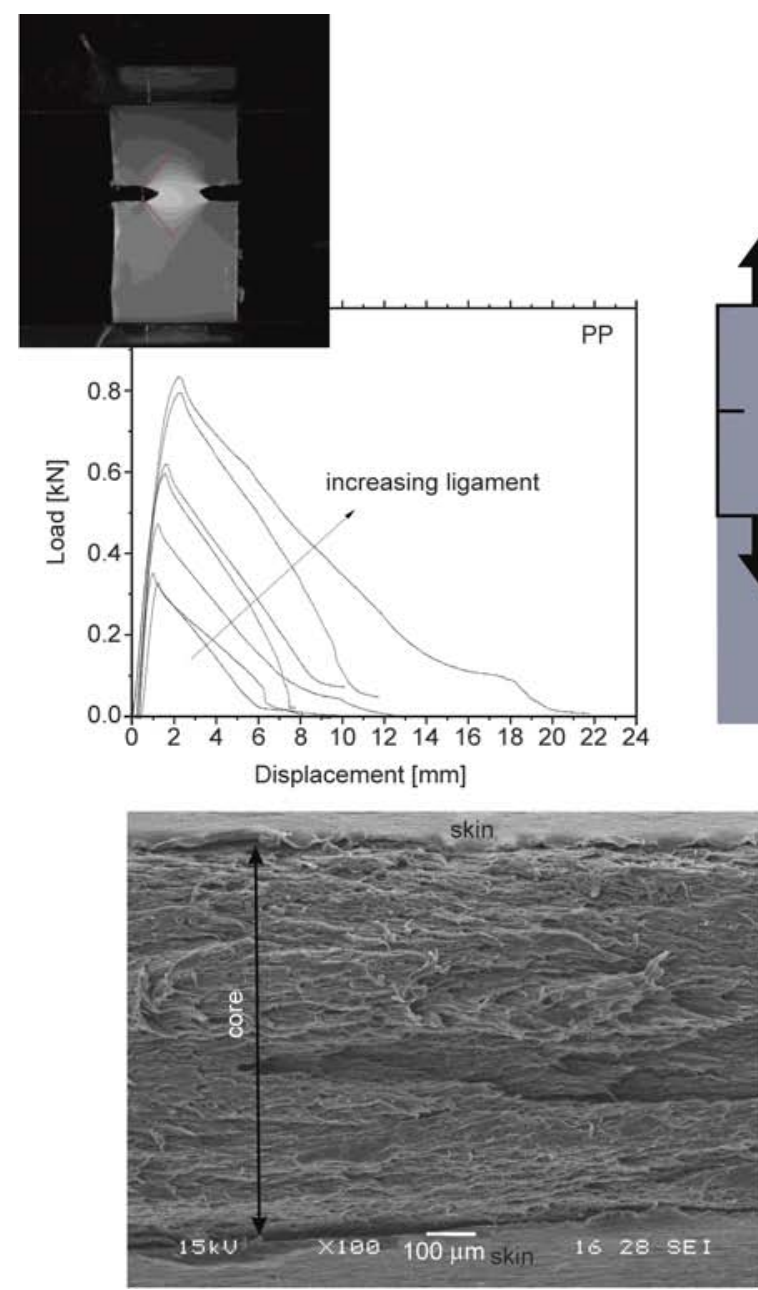
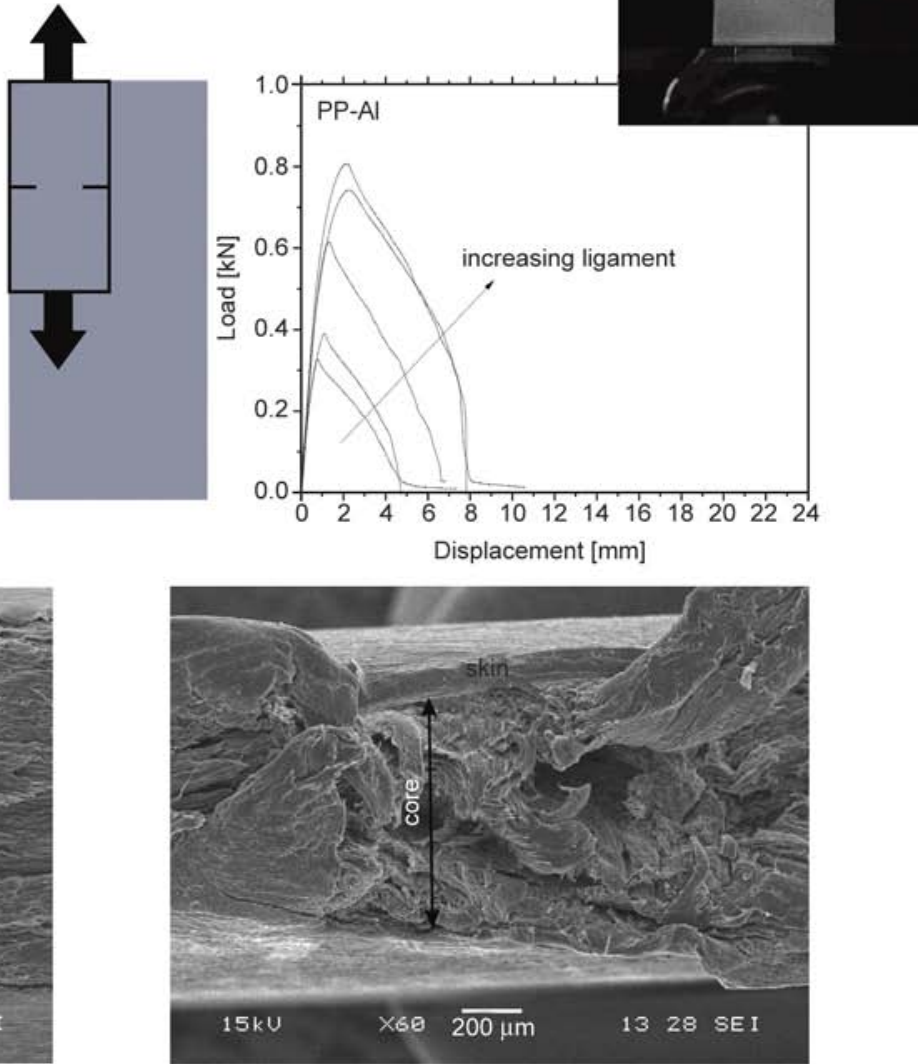

Figure 7. Typical load-displacement fracture curves away from weld line for PP and PP-Al. Developed plastic zones as seen in-situ and SEM micrographs of post-mortem fracture surfaces are also shown. 

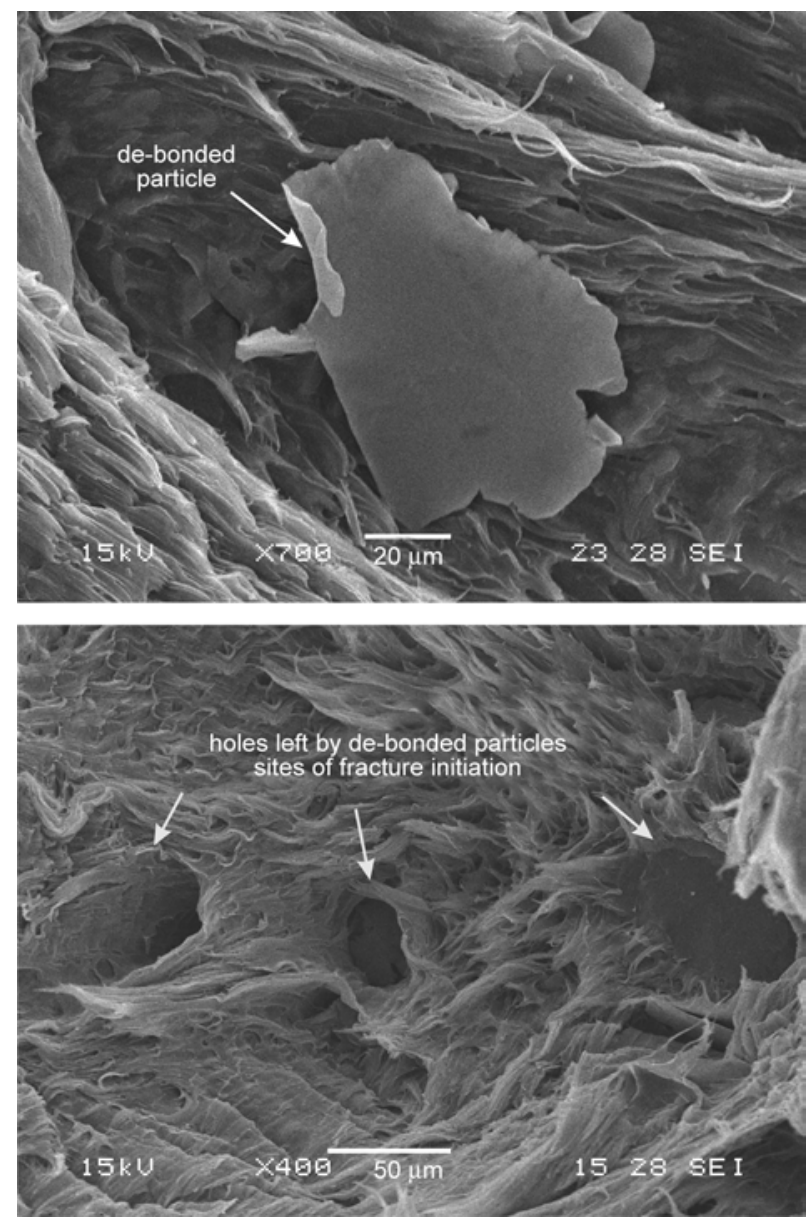

Figure 8. SEM micrographs of post-mortem fracture surfaces of PP-Al in which a de-bonded Al flake is clearly seen into deformed PP (a); and holes left by de-bonded particles are evidenced (b). It is clear from micrograph that these holes were points of fracture initiation.

all specific work $w_{\mathrm{f}}$ vs. $l$ curve can be obtained in which we and $\varphi w_{\mathrm{p}} l$ are the intercept and slope of a linear interpolation of the data. This analysis is shown in Figure 9. Consistently, initiation values $\left(w_{\mathrm{e}}\right)$ were

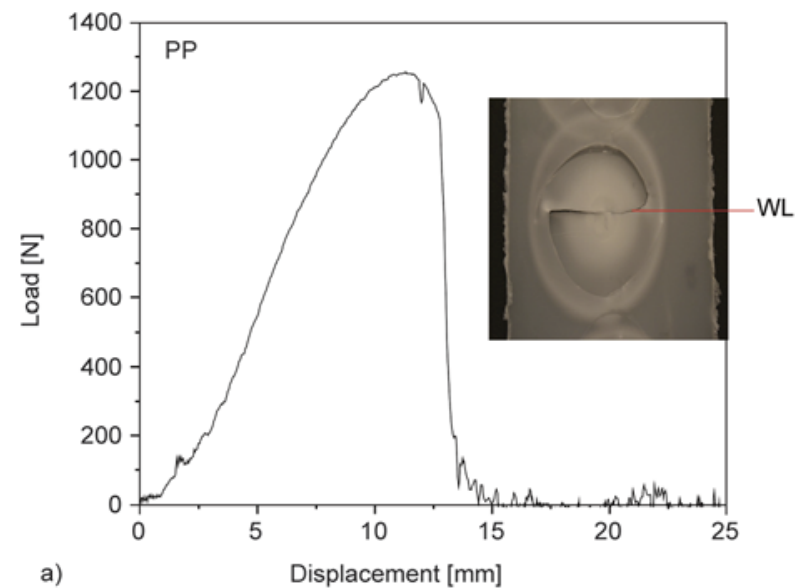

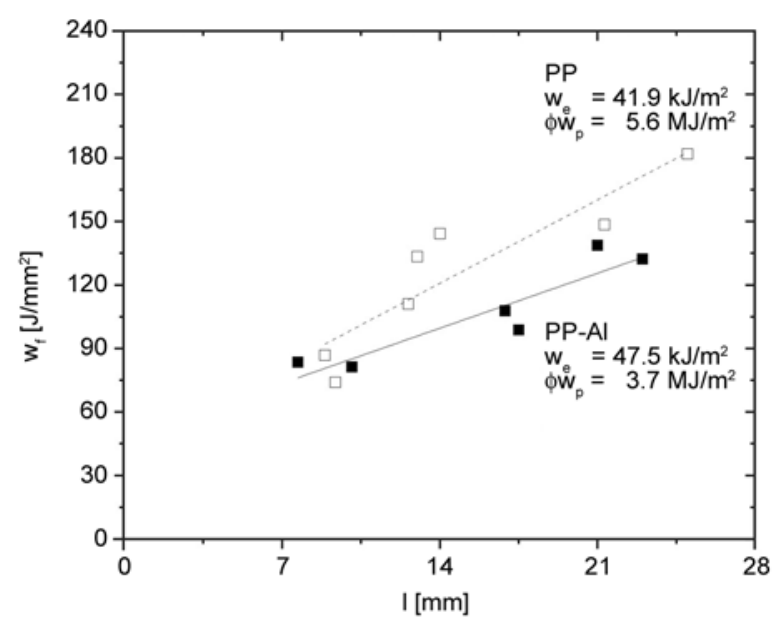

Figure 9. EWF plots

very similar, and some differences were seen in propagation stage $\left(\varphi w_{\mathrm{p}}\right)$. To quantify them, the shape factor $\varphi$ was determined - according to the EWF protocol [33] - by using the relation between $h$ (plastic zone height, measured from cross-polarized photos as the examples in Figure 7) and $l$ (for diamond plastic zone shape $\varphi=\pi h /(2 l)$ and for elliptical plastic zone $\varphi=\pi h /(4 l))$. $\varphi$ values of 1.24 and 0.23 were obtained for PP (diamond) and PP-Al (ellipse) respectively. From these values and $\varphi w_{\mathrm{p}}$ that emerged from the linear interpolation of $w_{\mathrm{f}}$ data (intercept), $w_{\mathrm{p}}$ (specific energy absorption per unit volume) equal to 4.51 and $16.01 \mathrm{MJ} / \mathrm{m}^{3}$ were estimated for PP and PP-Al respectively. These values indicate that much more energy is involved in the propagation of a crack in the PP of PP-Al samples than in the PP of neat PP samples.

Typical behavior of PP and PP-Al samples under biaxial impact loads at the weld line is shown in Figure 10. PP presented a semi ductile behavior with

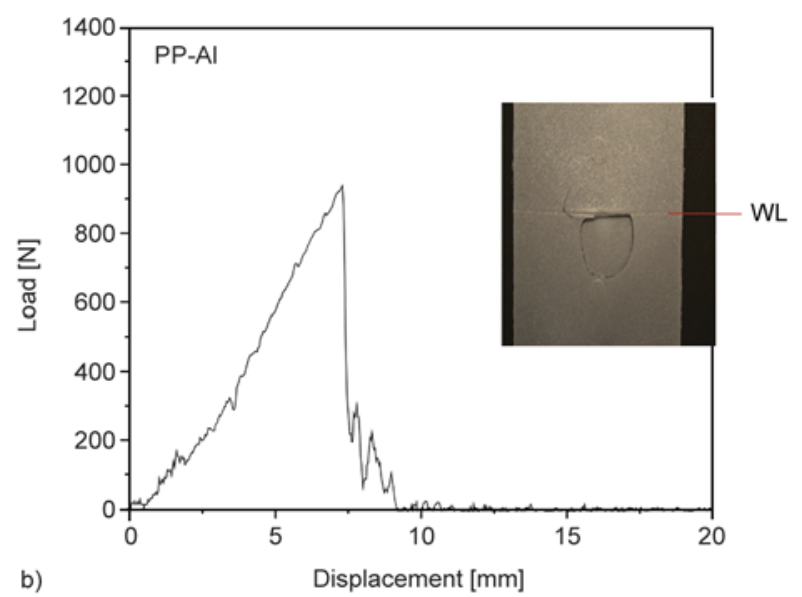

Figure 10. Typical behavior under biaxial impact at the weld line for (a) PP and (b) PP-Al moldings 


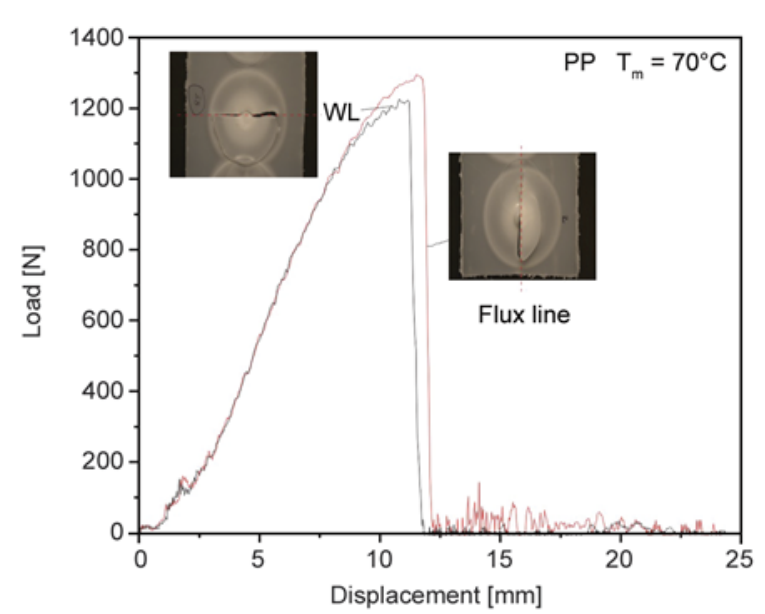

Figure 11. Comparison of behavior under biaxial impact at the weld line and near injection point (PP samples)

stress whitening before failure, while PP-Al exhibited a completely brittle failure. It is noticeable that as in quasi-static fracture tests, all samples (PP and $\mathrm{PP}-\mathrm{Al}$ ) failed following the weld line, i.e. it acted as a strong stress raiser defect. When samples were impacted at location near injection point a similar failure was observed, but now following flux lines. In Figure 11 a comparison between tests performed at the weld line and near injection point is shown. It was concluded that both weld lines and flux lines acted as stress raisers.

\section{Discussion}

Differences found in the fracture behavior and developed plastic zones in fracture samples suggested some micro-structural difference in PP induced by Al flakes. Therefore an analysis of the samples' morphology was done.

X-ray diffraction (XRD) was performed with a Phillips X'PERT MPD diffractometer in reflection mode $(\mathrm{Cu} \mathrm{K} \alpha$ radiation $\lambda=1.5418 \AA$, generator voltage $40 \mathrm{kV}$, current $40 \mathrm{~mA}$, sample to detector distance $240 \mathrm{~mm}$ ) to observe the PP structure in the skin and the core. The metallic pigment induced noticeable differences in the skin's PP morphology (Figure 12). Unexpectedly, the commercial pigment promoted the formation of $\beta$-PP (increase in (300) reflection (Figure 12a), decreasing crystallinity (decrease of reflections intensity). The fraction of $\beta$-phase in the crystalline phase of polypropylene was calculated by using the Turner Jones et al. [34] relation (Equation (6)):

$$
K_{\beta}=\frac{I_{300}^{\beta}}{I_{300}^{\beta}+I_{110}^{\alpha}+I_{040}^{\alpha}+I_{130}^{\alpha}}
$$
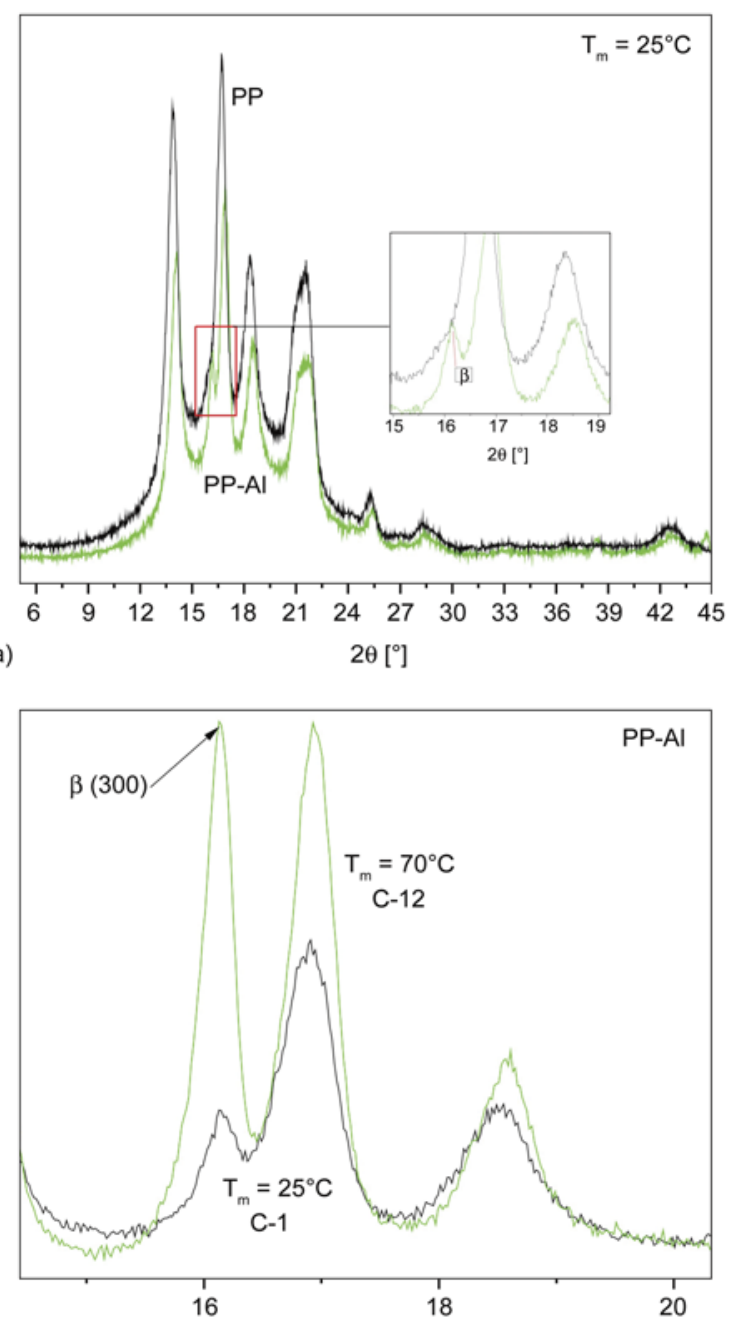

b) $2 \theta\left[^{\circ}\right]$

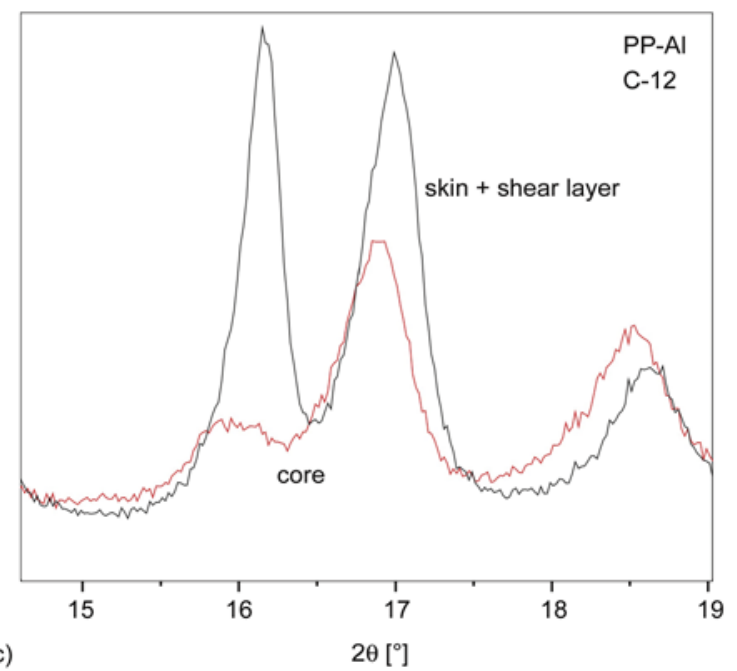

Figure 12. DRX curves of PP and PP/Al moldings. (a) condition 1 (b) processed at different temperatures (c) comparison between skin and core of PP-Al molding processed at condition 12

where in a generic sense $I_{\mathrm{abc}}^{\mathrm{i}}$ is the intensity of the $(a b c)$ crystal growing plane for each phase $i$. Mold temperature greatly influenced PP microstructure: 


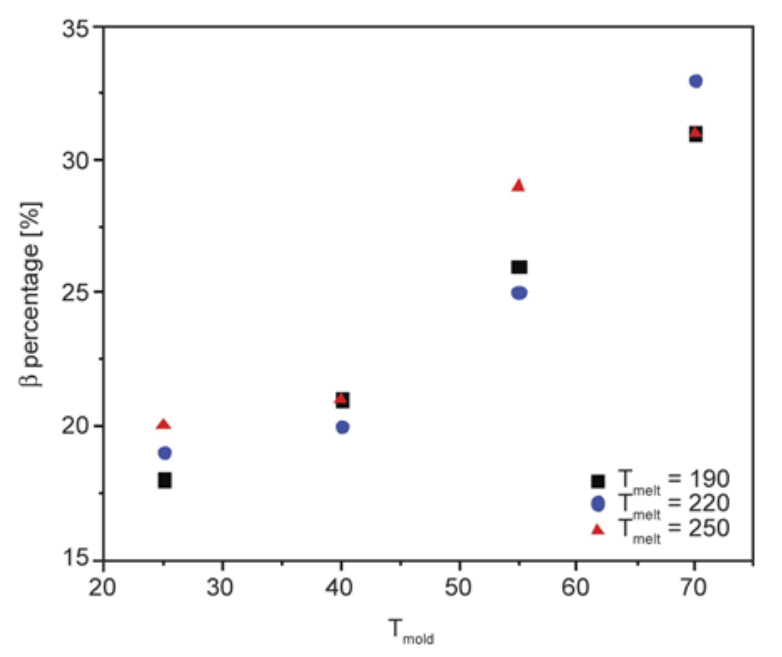

Figure 13. $\beta$-PP polymorph content in PP-Al samples for all processing conditions

Table 3. $\beta$ content $\left(K_{\beta}\right)$ in skin of samples of processing condition 12

\begin{tabular}{|l|c|c|}
\hline \multicolumn{1}{|c|}{ Sample } & $\mathbf{K}_{\boldsymbol{\beta}}$ in weld line & $\mathbf{K}_{\boldsymbol{\beta}}$ in bulk \\
\hline $\mathrm{PP}$ & 0.11 & 0.19 \\
\hline $\mathrm{PP}-\mathrm{Al}$ & 0.30 & 0.34 \\
\hline
\end{tabular}

increasing temperature in $45^{\circ} \mathrm{C}$ duplicated the percentage of $\beta$-PP in both $\mathrm{PP}$ and $\mathrm{PP} / \mathrm{Al}$ moldings (Figure12b and 13). It was also found that melt temperature does not influence the microstructure (Figure 13). An important finding is that there was a profile of $\beta$ content trough the samples (Table 3 presents results for processing condition 12 as an example). $K_{\beta}$ was lower in weld lines than away from them. Also big differences in $K_{\beta}$ were found between skin and core. The influence of mold temperature on $K_{\beta}$ is more pronounced in the close vicinity of the mold wall, i.e. in the specimens' skin: the 300 diffraction maximum of $\beta$-phase decreases from the skin to the core (see Figure $12 \mathrm{c}$ ). For example, $K_{\beta}$ diminished from 0.34 to 0.16 as moving from the skin to the core in PP-Al boxes away from weld lines. This fact can be easily explained remembering that while the skin solidifies nearly at the same temperature as mold temperature, the core crystallizes at notably higher temperature, which results in lower crystallinity changes.

The question to answer here is why $\mathrm{Al}$ pigment promotes $\beta$-polymorph if it is known to not being a nucleating agent for this polymorph in PP. Crystallization in a temperature gradient or in sheared melt, typical of injection molding, encourages the development of the $\beta$-phase in commercial non nucleated PP. But these conditions are present also in PP mold- ings. So, what is the effect of $\mathrm{Al}$ pigment? It is known that the growth rate of $\beta$ spherulites is up to $70 \%$ faster than that of $\alpha$-spherulites when conditions for $\beta$ nucleation are provided [35] and this rate presents a maximum at approximately $120^{\circ} \mathrm{C}$ [36]. When cooling is fast, the crystallization of $\beta$ form is favored. In fact Turner Jones et al. [34] produced large amounts of the $\beta$ form quenching a sample very rapidly to below $130^{\circ} \mathrm{C}$. Al pigment, which increased the thermal conductivity of PP composites [31], provided a faster cooling rate of the skin and therefore conditions for $\beta$-PP crystals to grow. It seems that the addition of $\mathrm{Al}$ flakes that increase the cooling rate combined with the high shear stresses of injection molding induced the formation of the $\beta$-PP.

According to these findings, differences in developed plastic zones in fracture tests can be explained by the differences in polymorphic phase: $\alpha$-PP develops a diamond shaped plastic zone and $\beta$-PP develops an elliptic plastic zone [37]. Also, differences in plastic behavior of skin and core are due in part by the presence of $\beta-P P$, which is more ductile and tough than $\alpha$-PP $[37,38]$. Even though $\beta$-PP is tougher and more ductile, Al particles acted as stress concentrators. In other words, the occurrence of $\beta$ $\mathrm{PP}$ in PP-Al moldings may counteract in part the diminishment of PP toughness induce by Al flakes. Under impact conditions, these benefits of the $\beta$ phase are mostly inhibited by solicitation mode (biaxial), and the processing defects (flow lines and weld lines) prevailed.

\section{Conclusions}

The addition of Al particles in PP matrix has influence on the aesthetical, morphological and mechanical properties of injection molded parts. The metallic looking effect is easily obtained when these particles are used, at low weight percentages (max $2 \%$ ). However, several types of undesired effects appear, such as weld lines and warpage that are dependent on the processing conditions used.

In terms of aesthetics effects, high melt temperatures diminish differential shrinkage and welding lines are less noticeable, indicating that aesthetic aspects could be improved by manipulating processing conditions. Weld lines appeared wider and diffuser with increasing melt temperature.

Morphology analysis showed a distinction between PP and PP-Al molded parts. Al particles increased thermal conductivity of PP generating a thicker skin, 
which combined with an inherent gradient temperature and typical shear stresses developed during injection molding, induced the formation of $\beta$-PP phase. This effect was found to be dependent of processing conditions: higher melt temperature induced higher $\beta$-PP content.

Mechanical performance of parts showed to be dependent on PP morphology. Under quasi-static loading conditions plastic zones of PP samples were diamond shaped (typical of $\alpha$-PP) while PP-Al pieces developed elliptic plastic zones (typical of $\beta$ $\mathrm{PP})$. Also, differences in propagation mode were observed in SEM. The occurrence of $\beta$-PP in PP-Al moldings counteracts the detrimental effect of not bonded Al flakes, and PP-Al moldings have similar toughness as PP moldings, under triaxial quasi-static loading conditions.

However, under biaxial impact loading these beneficial effects of $\beta$ polymorph are inhibited, and the defects induced by Al flakes orientation and their poor adhesion to the PP matrix prevailed lowering toughness.

\section{Acknowledgements}

Authors would like to thank CONICET, ANPCyT and UNMdP for financial support.

\section{References}

[1] Wheeler I.: Metallic pigments in polymers. Rapra, Shawbury (1999).

[2] Rusu M., Sofian N., Rusu D.: Mechanical and thermal properties of zinc powder filled high density polyethylene composites. Polymer Testing, 20, 409-417 (2001). DOI: 10.1016/S0142-9418(00)00051-9

[3] Gungor A.: The physical and mechanical properties of polymer composites filled with Fe-powder. Journal of Applied Polymer Science, 99, 2438-2442 (2006). DOI: 10.1002/app.22637

[4] Luyt A. S., Molefi J. A., Krump H.: Thermal, mechanical and electrical properties of copper powder filled low-density and linear low-density polyethylene composites. Polymer Degradation and Stability, 91, 16291636 (2006).

DOI: $10.1016 /$ j.polymdegradstab.2005.09.014

[5] Bunge H.: Metallic looking plastics with new silver and colored aluminum pigments. in 'Annual Technical Conference-ANTEC, Atlanta, USA’ 2586-2588 (1998).

[6] Kobayashi Y., Teramoto G., Kanai T.: The unique flow of polypropylene at the weld line behind an obstacle in injection molding. Polymer Engineering and Science, 51, 526-531 (2011). DOI: $10.1002 /$ pen. 21841
[7] Harris R. M.: Coloring technology for plastics. William Andrew Publishing, New York (1999).

[8] Park J. M., Jeong S. J., Park S. J.: Flake orientation in injection molding of pigmented thermoplastics. Journal of Manufacturing Science and Engineering, 134, 014501/1-014501/4 (2012).

DOI: $10.1115 / 1.4005309$

[9] Martins C., Pontes A., Santos I.: On the effect of metallic particles on the performance of injection molded PP plastic parts. in 'Proceedings of International Conference on Polymers and Moulds Innovations, Ghent, Belgium' 375-382 (2012).

[10] Santos I., Pontes A., Martins C.: Morphological aspects of injection-molded polypropylene with metallic pigments. in 'ANTEC 2013 Conference Proceedings, Cincinnati, USA' p.5 (2013).

[11] Liu G., Edward G.: Correlation between morphology distribution of injection molded polypropylene and processing history identified by numerical simulation. Journal of Injection Molding Technology, 5, 133-140 (2001).

[12] Lotz B., Wittmann J. C., Lovinger A. J.: Structure and morphology of poly(propylenes): A molecular analysis. Polymer, 37, 4979-4992 (1996).

DOI: 10.1016/0032-3861(96)00370-9

[13] Jacoby P., Bersted B. H., Kissel W. J., Smith C. E.: Studies on the $\beta$-crystalline form of isotactic polypropylene. Journal of Polymer Science Part B: Polymer Physics, 24, 461-491 (1986).

DOI: $10.1002 /$ polb.1986.090240301

[14] Shi G., Zhang X.: Effect of $\beta$-nucleator content on the crystallization and melting behaviour of $\beta$-crystalline phase polypropylene. Thermochimica Acta, 205, 235243 (1992).

DOI: 10.1016/0040-6031(92)85265-W

[15] Tjong S. C., Shen J. S., Li R. K. Y.: Mechanical behavior of injection molded $\beta$-crystalline phase polypropylene. Polymer Engineering and Science, 36, 100-105 (1996).

DOI: $10.1002 /$ pen. 10390

[16] Liu J., Wei X., Guo Q.: The $\beta$-crystalline form of wollastonite-filled polypropylene. Journal of Applied Polymer Science, 41, 2829-2835 (1990). DOI: 10.1002/app.1990.070411125

[17] Medellín-Rodríguez F. J., Mata-Padilla J. M., Hsiao B. S., Waldo-Mendoza M. A., Ramírez-Vargas E., SánchezValdes S.: The effect of nanoclays on the nucleation, crystallization, and melting mechanisms of isotactic polypropylene. Polymer Engineering and Science, 47, 1889-1897 (2007).

DOI: $10.1002 /$ pen.20902

[18] Lovinger A. J., Chua J. O., Gryte C. C.: Studies on the $\alpha$ and $\beta$ forms of isotactic polypropylene by crystallization in a temperature gradient. Journal of Polymer Science: Polymer Physics Edition, 15, 641-656 (1977). DOI: $10.1002 /$ pol.1977.180150405 
[19] Dragaun H., Hubeny H., Muschik H.: Shear-induced $\beta$-form crystallization in isotactic polypropylene. Journal of Polymer Science: Polymer Physics Edition, 15, 1779-1789 (1977).

DOI: $10.1002 /$ pol.1977.180151008

[20] Somani R. H., Hsiao B. S., Nogales A., Fruitwala H., Srinivas S., Tsou A. H.: Structure development during shear flow induced crystallization of i-PP: In situ wideangle X-ray diffraction study. Macromolecules, 34, 5902-5909 (2001).

DOI: $10.1021 / \mathrm{ma} 0106191$

[21] Farah M., Bretas R. E. S.: Characterization of i-PP shear-induced crystallization layers developed in a slit die. Journal of Applied Polymer Science, 91, 35283541 (2004).

DOI: 10.1002/app.13576

[22] Kotek J., Raab M., Baldrian J., Grellmann W.: The effect of specific $\beta$-nucleation on morphology and mechanical behavior of isotactic polypropylene. Journal of Applied Polymer Science, 85, 1174-1184 (2002). DOI: 10.1002/app.10701

[23] Karger-Kocsis J., Varga J.: Effects of $\beta$ - $\alpha$ transformation on the static and dynamic tensile behavior of isotactic polypropylene. Journal of Applied Polymer Science, 62, 291-300 (1996).

DOI: 10.1002/(SICI)1097-4628(19961010)62:2<291::

$$
\text { AID-APP4>3.0.CO;2-S }
$$

[24] Fitchmun D. R., Mencik Z.: Morphology of injectionmolded polypropylene. Journal of Polymer Science: Polymer Physics Edition, 11, 951-971 (1973).

DOI: $10.1002 /$ pol.1973.180110512

[25] Viana J. C., Cunha A. M., Billon N.: The thermomechanical environment and the microstructure of an injection moulded polypropylene copolymer. Polymer, 43, 4185-4196 (2002).

DOI: $10.1016 / \mathrm{S} 0032-3861(02) 00253-7$

[26] Demiray M., Isayev A.: Effect of processing conditions on crystallinity and microstructure of injection moldings of polypropylenes of various molecular weights. in 'SPE ANTEC '96 Conference proceedings, Indianapolis, USA' 1576-1580 (1996).

[27] Williams J.: $K_{\mathrm{c}}$ and $G_{\mathrm{c}}$ at slow speeds for polymers. in 'Fracture mechanics testing methods for polymers, adhesives and composites' (eds.: Moore D. R., Williams J. G., Pavan A.) Elsevier, Amsterdam, Vol 28, 11-26 (2001).

DOI: $10.1016 / \mathrm{S} 1566-1369(01) 80025-X$

[28] Adams M. J., Williams D., Williams J. G.: The use of linear elastic fracture mechanics for particulate solids. Journal of Materials Science, 24, 1772-1776 (1989). DOI: $10.1007 / \mathrm{BF} 01105704$
[29] Cunha A., Pouzada A. S., Crawford R. J.: A study of the impact behaviour of injection moulded polypropylene using two different modes of testing. Plastics Rubber and Composites Processing and Applications, 18, 7990 (1992).

[30] Viana J., Cunha A. M., Billon N.: The tensile behaviour of an injection-moulded propylene-ethylene copolymer: The effect of the local thermomechanical processing conditions. Polymer International, 43, 159166 (1997).

DOI: 10.1002/(SICI)1097-0126(199706)43:2<159::AIDPI720>3.0.CO;2-X

[31] Boudenne A., Ibos L., Fois M., Gehin E., Majeste J-C.: Thermophysical properties of polypropylene/aluminum composites. Journal of Polymer Science Part B: Polymer Physics, 42, 722-732 (2004).

DOI: $10.1002 /$ polb.10713

[32] Rawson K. W., Allan P. S., Bevis M. J.: Controlled orientation of reflective pigment and optical property characterization of injection-molded polypropylene. Polymer Engineering and Science, 39, 177-189 (1999). DOI: $10.1002 /$ pen. 11406

[33] Clutton E.: Essential work of fracture. in 'Fracture mechanics testing methods for polymers, adhesives and composites' (eds.: Moore D. R., Williams J. G., Pavan A.) Elsevier, Amsterdam, Vol 28, 177-195 (2001). DOI: $10.1016 / \mathrm{S} 1566-1369(01) 80033-9$

[34] Turner Jones A., Aizlewood J. M., Beckett D. R.: Crystalline forms of isotactic polypropylene. Die Makromolekulare Chemie, 75, 134-158 (1964).

DOI: $10.1002 / \mathrm{macp} .1964 .020750113$

[35] Bviickner S., Meille S.: Polymorphism in crystalline polypropylene. in 'Polypropylene' (Ed.: Karger-Kocsis J.) Kluwer, Dodrecht, 606-614 (1999).

[36] von Leugering H. J., Kirsch G.: Beeinflussung der Kristallstruktur von isotaktischem Polypropylen durch Kristallisation aus orientierten Schmelzen (in German). Die Angewandte Makromolekulare Chemie, 33, 17-23 (1973). DOI: 10.1002/apmc.1973.050330102

[37] Karger-Kocsis J.: How does 'phase transformation toughening' work in semicrystalline polymers? Polymer Engineering and Science, 36, 203-210 (1996).

DOI: $10.1002 /$ pen.10403

[38] Chen H. B., Karger-Kocsis J., Wu J. S., Varga J.: Fracture toughness of $\alpha$ - and $\beta$-phase polypropylene homopolymers and random- and block-copolymers. Polymer, 43, 6505-6514 (2002).

DOI: $\underline{10.1016 / \mathrm{S} 0032-3861(02) 00590-6}$ 